\title{
Pengembangan Aplikasi Bahan Ajar Kalkulus 1 Berbasis Android
}

\author{
Perani Rosyani ${ }^{1}$, Devi Yunita ${ }^{2}$ \\ Fakultas Tehnik, Tehnik Informatika, Universitas pamulang, Pamulang, Indonesia \\ e-mail: $\left\{{ }^{1}\right.$ dosen00837; ${ }^{2}$ dosen00846\}@unpam.ac.id
}

\begin{abstract}
Teaching materials are the most important part of learning activities. The presence of instructional materials makes it easy for lecturers and students to give lectures and exercises in lectures especially for calculus courses. Calculus is a branch of mathematics which contains derivatives, integrals, limits, and infinite series. Calculus plays an important role in the fields of science, engineering, and economics. But some students are many who don't like the subject. Because the pattern of giving material from lecturers is less effective so students cannot develop calculus in their daily lives, especially in the field of technology. The purpose of this paper is to develop instructional material media that were previously traditional in the form of paper media and developed into an android based so that students can learn anywhere and anytime by assisting from smartphone phones. So, students can have interest and can develop theories that are in calculus in everyday life, especially in the field of technology
\end{abstract}

Keywords: calculus, IDEAL Problem Solving, android

\section{Pendahuluan}

Pembelajaran adalah sebuah proses menjalin hubungan dua arah antara pendidik dan peserta didik. Pembelajaran dapat diartikan pula sebagai bentuk kombinasi yang tersusun meliputi unsur manusia, material, fasilitas, perlengkapan dan prosedur yang saling mempengaruhi untuk mencapai tujuan pembelajaran (Lazuardy \& Tonni, 2016).

Kalkulus merupakan cabang ilmu matetamtka yang dapat menganalisa masalah yang berubah-ubah. Kalkulus terfiri dari pembahasan tentang turunan, integral, limit dan deret tak terhingga. kalkulus memegang peranan penting pada bidang-bidang sains, teknik, dan ekonomi. Ilmu kalkulus masuk kedalam matakuliah dasar di tingkat penguruan tinggi. Ilmu kalkulus bisa meningkatkan logika berpikir mahasiswa di perguruan tinggi.

Dalam proses pembelajaran konvensional, dosen biasanya memberikan penjelasan sambal memberikan cerah dan mencatat di papan tulis. Sedangkan Mahasiswa menyalin catatan tersebut sambil menyimak ceramah dari dosen. Sehingga proses pembelajaran lebih banyak mendengarkan ceramah dari dosen. Proses belajar mengajar di kelas tidaklah cukup untuk mempelajari dan memahami ilmu mengenai kalkulus, sehingga diperlukannya media tambahan untuk menambah ilmu tentang kalkulus.
Karena pentingnya mempelajari kalkulus, banyak buku-buku yang beredar yang membahas mengenai ilmu kalkulus yang bisa menambah pengetahuan tentang kalkulus. Proses pembelajaran tersebut dapat dilakukan dengan cara membaca buku. Pola pembelajaran ini yang membuat mahasiswa kurang aktif dan tidak dapat mengembangkan kemampuan yang mereka miliki. Mahasiswa di dalam kehidupan sehari-hari belum dapat mengaplikasikan secara teori, khususya di dalam bidang teknologi. Dengan adanya masalah tersebut dosen sebagai pendidik harus melakukan evaluasi diri dalam penyamaian materi, agar bisa menggali potensi mahasiswa tersebut. Kalkulus merupakan materi yang berkembang secara statis, mata kuliah kalkulus merupakan mata kuliah yang sudah baku untuk masing-masing pengguna karena tidak mengalami perubahan untuk jangka waktu yang pendek(Djohan, 2007) namun perlu direvisi secara berkala adalah tehnik penyajiannya (Purnomo, Fathurohman, \& Budiharto, 2014).

Salah satu tehnik penyajian yang akan diterapkan di dalam penelitian ini adalah menggunakan model IDEAL Problem Solving. Model pemecahan masalah ini memiliki langkahlangkah a. pengidentifikasi masalah (Identify the problem), b. pendefinisikan tujuan (Define the Goal), c. mencari solusi (Explore solution), d. pelaksanakan strategi (Act strategy), e. pengkajian kembali dan mengevaluasi dampak dari pengaruh 
(Look back and Evaluate the effect) (Bransford \& Stein, 1993).

Dengan adanya perkembangan teknologi telepon selular saat ini sangatlah pesat. Penerapan model IDEAL Problem Solving dapat dikombinasi dalam sistem operasi android. Yang mana sistem operasi android dalam bentuk telepon pintar (smartphone) ini menjadi trend yang digunakan saat ini untuk menjalankan banyak aplikasi mobile sebagai media untuk pengaksesan data dan pengolahan informasi. Informasi yang dimuat dalam buku mulai tergantikan dengan media digital. Di samping itu, jika dilihat dari nilai praktisnya, informasi yang dimuat dalam bentuk buku memang mudah untuk dibawa kemana-mana, tetapi akan lebih baik jika informasi dalam bentuk buku diubah kedalam bentuk digital, karena akan lebih mudah lagi untuk di genggam karena ukurannya yang kecil dan lebih praktis diharapkan dapat menumbuhkan keaktifan mahasiswa dalam mempelajari mata kuliah kalkulus dimanapun dan kapanpun.

Dengan melihat permasalahan diatas maka salah pemecahan masalah untuk membantu proses pembelajaran konvesional tersebut adalah dengan menggunakan media pembelajaran yang lebih simple (Astiti, 2015).Yaitu dengan media pembelajaran berbasis android sebagai aplikasi didalam sebuah smartphone yang berfungsi sebagai media penyajian informasi yang dapat diakses dengan mudah, cepat, dan praktis.

\section{Metode Penelitian}

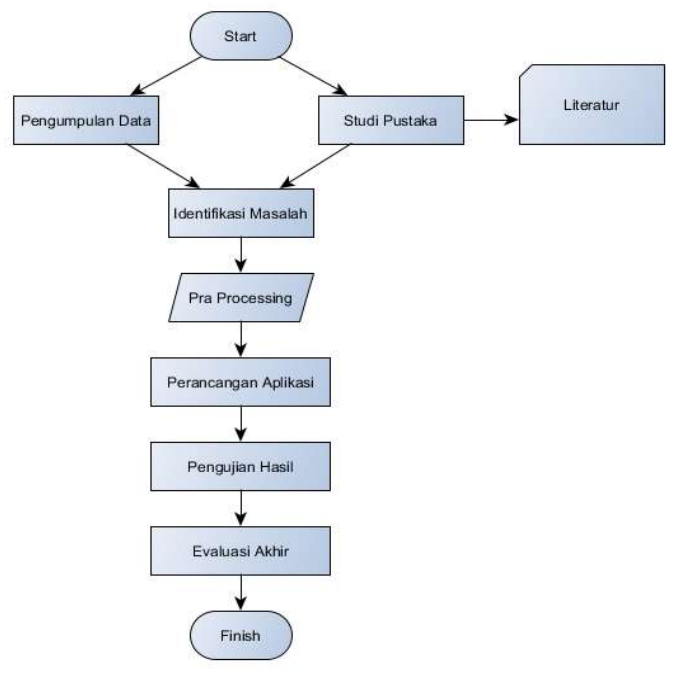

Gambar 1. Alur Penelitian a. Jenis Penelitian

Penelitian didalam paper ini termasuk jenis penelitian dan pengembangan (research and development) yaitu pengembangan dari sebuah aplikasi perangkat pembelajaran. (Fathurohman, n.d.) perangkat yang dikembangkan meliputi SAP dan penerapan materi. Adapun alur penelitian yang akan kita laksanakan ditunjukkan pada Gambar 1.

Keterangan Gambar 1:

1. Pengumpulan Data

Pengumpulan Data didalam penelitian ini dilakukan untuk memperoleh data dan informasi sehingga dapat tercapai tujuan yang diharapkan

2. Studi Pustaka

Untuk mencapai tujuan yang akan kami capai maka perlu di perlajari teori-teori yang terkait dengan penelitian ini seperti jurnal atau buku.

3. Identifikasi Masalah

Pada tahap ini dilakukan setelah semua data-data terpenuhi, lalu di ambil permasalahannya

4. Praprocessing

Persiapan data-data yang akan di pilih kedalam penentuan model

5. Perancangan Aplikasi

Pada tahapan ini akan dilakukan penentuan model IDEAL Problem Solving berbasis Android untuk perancangan bahan ajar kalkulus. Pembuatan aplikasi ini menggunakan Android Studio

6. Pengujian Hasil

Melakukan Testing terhadap hasil perancangan

7. Evaluasi Akhir

Pengujian hasil ini adalah untuk menguji apakah aplikasi yang dibuat sudah sesuai dengan tujuan dari penelitian ini

b. Waktu dan Lokasi Penelitian

Penelitian ini dilakukan di Jurusan Tehnik Informatika Universitas Pamulang. Rentang waktu penelitian ini kurang lebih 6 bulan dari pengumpulan data hingga penyelesaian yaitu Bulan Mei 2018 sampai dengan Oktober 2018.

c. Sarana Pendukung

Sarana pendukung dalam penelitian ini berupa laptop ASUS 15,6" dengan memory DDR3 8GB, sedangkan software yang 
digunakan adalah android studio dengan menggunakan Bahasa pemograman java.

d. Populasi dan sampel penelitian

Populasi penelitian ini diambil dari daftar mahasiswa mata kuliah kalkulus I jurusan tehnik Informatika Universitas Pamulang tahun ajaran 2017-2018.

e. Tehnik Pengumpulan Data

Dalam penelitian ini data yang dikumpulkan adalah data-data bersifat tekstual. Data tersebut terkumpul melalui studi literatur yang berbedabeda, seperti jurnal, conference paper, e-book dan text book.

f. Metode Pengembangan sistem

Sistem yang dikembangkan didalam penelitian ini menggunakan metode sistem Luther yang mana memiliki proses secara berurutan dari konsep hingga distribusi.

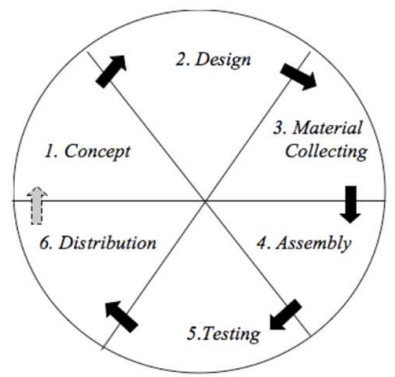

Gambar 2. Model Pengembangan sistem Luther berikut:

Penjelasan mengenai gambar di atas sebagai

1. Pembuatan Konsep (Concept)

Dalam tahapan awal ini merupakan tahap untuk menentukan tujuan dan siapa yang akan menggunakan aplikasi ini.

2. Melakukan Perancangan (Design)

Tahap kedua merupakan tahap perancangan, didalam tahapan ini kami merancang bagaimana tampilan interface dan kebutuhan untuk aplikasi ini.

3. Pengumpulan Bahan (Material Colleting) Pengumpulan bahan merupakan tahapan pengumpulan bahan untuk keperluan aplikasi in seperti gambar, teks dan audio.

4. Pembuatan (Assembly)

Didalam tahap ini dimana semuah bahan dibuat untuk sebuah aplikasi

5. Pengujian (Testing)

Pengujian ini dilakukan untuk menilai apakah tahap pembuatan aplikasi ini memiliki kesalahan atau tidak serta melihat apakah aplikasi suda sesuai dengan yang diharapkan.
6. Distribusi (Distribution)

Ini merupakan tahap akhir dimana aplikasi disimpan untuk dapat didistribusikan kepada pengguna.

\section{Hasil dan pembahasan}

Kegiatan tatap muka merupakan kegiatan utama didalam sebuah proses pembelajaran. Kegiatan tatap muka merupakan sebuah ativitas dimana dosen dan mahasiswa berkomunikasi 2 arah dalam memecahkan atau menganalisis kasus sebagai penerapan konsep sebuah pembelajaran. Tahapan pertama didalam kegiatan pembelajaran menggunakan metode IDEAL problem solving adalah 1. mengidentifikasi masalah dimana dosen sebagai indicator untuk menjelaskan materi yang dibutuhkan, sedangkan mahasiswa mencoba mencermati, memahami dan mencari permasalahan yang dijelaskan oleh dosen, 2. Mendefinisikan tujuan merupakan tahap kedua dimana dosen membantu mahasiswa untuk menjelaskan dan mengelompokan tugas yang berhubungan dengan kasus-kasus yang diberikan, sedangkan mahasiswa membentuk sebuah team diskusi untuk menyiapkan bahan-bahan, 3 . Menggali solusi dapat dilakukan dengan cara mendorong mahasiswa untuk menemukan jawab atas permasalahan yang dibahas serta mendefinisikannya, sedangkan aktivitas mahasiswa adalah mempelajari materi atau literatur pendukung dan mendiskusikan masalah yang diberikan, 4. Didalam melaksanakan solusi/strategi ini aktivitas dosen adalah membantu mahasiswa dalam merencanakan dan menyiapkan untuk menyelsaikan masalah dari kasus yang diberikan, sedangkan aktivitas mahasiswa meliputi menulis dengan rapih hasil dari perencanaan yang telah didiskusikan, 5. Tahap terakhir adalah menganalisa dan mengevalusi dengan membantu mahasiswa mengevaluasi setiap proses yang sudah dilakukan mahasiswa dari awal hingga akhir sehingga dapat ditarik sebuah kesimpulan untuk penilaian mahasiswa, sedangkan aktivitas mahasiswa didalam tahapan ini adalah melakukan evalusi dan perbaikan jika ada kesalahan.

Berdasarkan metode penelitian diatas maka hasil dan pembahasan sebagai berikut.

a. Use Case

Use case merupakan penjelasan atau gambaran interaksi yang terjadi antara aktor dengan inisiator dari hubungan sistem yang ada. 


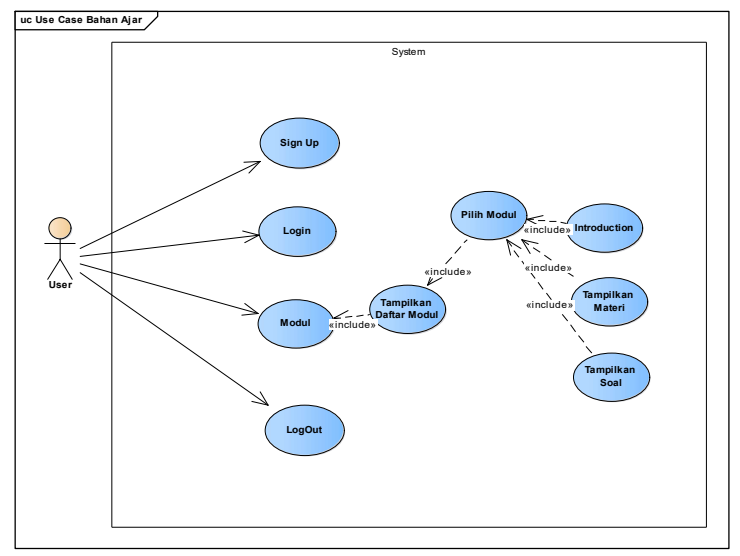

Gambar 3. Use Case

Gambar usecase di atas merupakan tahapan perencanaan untuk tampilan userinterface, adapun keterangan mengenai gambar usecase diatas

Tabel 1. Keterangan Use Case

\begin{tabular}{|c|c|c|}
\hline No & Deskripsi & Keterangan \\
\hline 1 & $\begin{array}{l}\text { Aktor : User } \\
\text { Use Case : Sign } \\
\text { Up }\end{array}$ & $\begin{array}{l}\text { Didalam case ini } \\
\text { Pengguna harus } \\
\text { melakukan } \\
\text { registrasi dulu } \\
\text { jika belum } \\
\text { memiliki akun, } \\
\text { registrasi ini } \\
\text { berisi biodata diri } \\
\text { si user } \\
\end{array}$ \\
\hline 2 & $\begin{array}{l}\text { Aktor : User } \\
\text { Use Case : login }\end{array}$ & $\begin{array}{ll}\text { - } & \text { Pengguna dapat } \\
\text { masuk kedalam } \\
\text { menu pilih modul } \\
\text { jika sudah } \\
\text { memiliki akun } \\
\end{array}$ \\
\hline 3 & $\begin{array}{l}\text { Aktor : User } \\
\text { Use Case : modul }\end{array}$ & $\begin{array}{l}\text { Pengguna dapat } \\
\text { memilih modul } \\
\text { sesuai materi } \\
\text { yang akan di } \\
\text { bahas. Modul ini } \\
\text { isinya ada } \\
\text { beberapa sesuai } \\
\text { RPS yang di } \\
\text { tentukan } \\
\end{array}$ \\
\hline 4 & $\begin{array}{l}\text { Aktor: User } \\
\text { Use Case: } \\
\text { LogOut }\end{array}$ & $\begin{array}{l}\text { Pengguna dapat } \\
\text { keluar dari } \\
\text { aplikasi ini }\end{array}$ \\
\hline
\end{tabular}

b. Tampilan Interface

User interface merupakan bentuk tampilan atau rancangan secara grafis yang menghubungkan langsung dengan pengguna (user). Tampilan interface ini berfungsi untuk menghubungkan antara manusia dengan sistem yang sedang berlangsung. Tampilan ini menerapkan tampilan menu-menu yang sederhana dengan background warna hijau tosca. Berikut adalah tampilan interface yang di usulkan.

- Tampilan Awal

Tampilan awal berisi logo dari Universitas Pamulang karena penulis ingin memperkenal bahwa aplikasi ini di gunakan untuk keperluan civitas universitas pamulang. Adanya username sebagai pengenal siapa saja yang bisa akses kedalam aplikasi ini. Password untuk kunci akses kedalam aplikasi serta register untuk user yang belum memiliki akun sebelumnya. Didalam menu register ini user akan di minta biodata diri berupa nama, tempat tanggal lahir, alamat email serta nomor handphone.Tampilan ini dibuat sederhana karena melambangkan efesiensi pembelajaran.

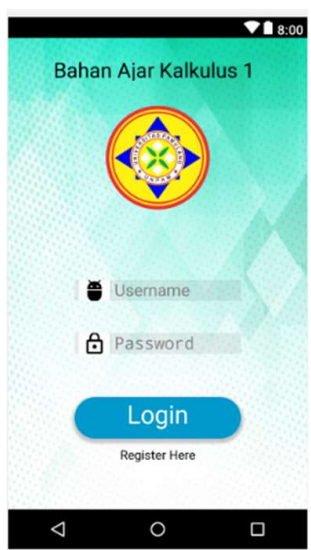

Gambar 4. Tampilan awal

- Tampilan Modul

Didalam tampilan modul berisi modul yang sesuai RPS yang di rancang diantaranya adalah definisi dari sistem bilangan yang membahas beberapa jenisjenis bilangan serta implementasi didalam bentuk ketaksamaan, pertidaksamaan yang mewakili pertidaksamaan linear, kuadrat, bentuk pecahan dan pertidaksamaan nilai mutlak. Modul definisi penyajian fungsi, didalam modul penyajian fungsi ini terkait dengan fungsi linear, kuadrat, bentuk pecahan dan nilai mutlak. Didalam modul limit, didalamnya menyajikan sifat-sifat berserta jenis-jenis limit dari limit aljabar hingga limit trigonometri. Modul 
selanjutnya adalah turunan dimana membahas tentang jenis-jenis turunan. Didalamnya di bahas juga turunan trigonometri.

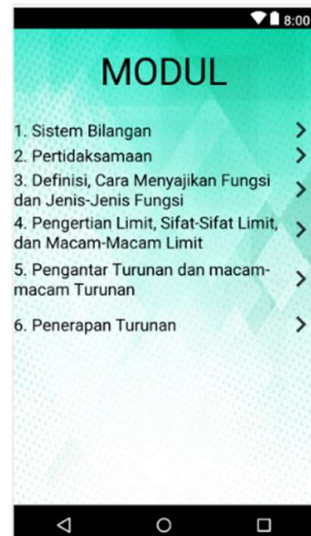

Gambar 5. Tampilan Modul

- Tampilan pendahuluan

Isi dari tampilan pendahuluan ini berupa sub pokok pembahasan, tujuan pembelajaran serta lamanya proses penyelesaian modul. Didalam sub pokok pembahasan dijelaskan materi-materi yang akan di bahas selama menggunakan modul tersebut. Tujuan pembelajaran merupakan sasaran yang akan dicapai selama proses pembelajaran dari awal hingga akhir. Metode yang digunakan merupakan bagaimana cara dosen memberikan materi kepada mahasiswanya yaitu dengan metode ceramah dan latihan yang di lakukan didalam kelas. Kapasitas waktu menunjukan keperluan dosen untuk menyelesaikan materi-materi yang dibahas.

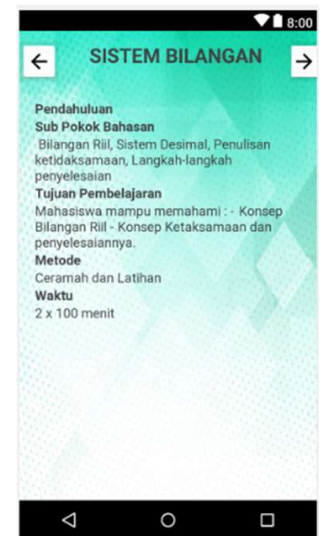

Gambar 6. Tampilan Pendahuluan
- Tampilan Materi

Berisi materi dan soal yang akan di bahas ataupun didiskusikan. Materi didalam aplikasi ini didesain dengan simple agar mudah dimengerti.

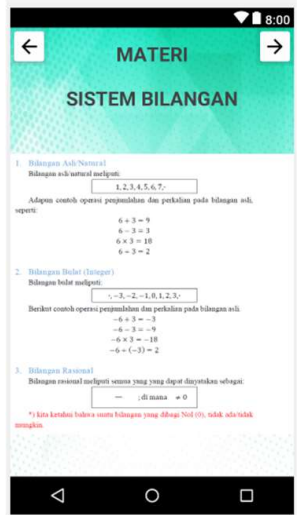

Gambar 7. Tampilan Menu Materi

\section{Kesimpulan}

Berdasarkan Analisa dan perancangan bahan ajar kalkulus berbasis android ini maka penulis menyimpulkan sebagai berikut.

a. Aplikasi ini dapat bermanfaat dan membantu mahasiswa untuk meningkatkan minat belajar khususnya untuk mata kuliah Kalkulus

b. Aplikasi ini dapat menjadi alternative sebagai media pembelajaran yang inovatif karena berbasis android yang didukung dengan handphone smartphone sehingga lebih praktis untuk belajar dimanapun dan kapanpun.

\section{Saran}

Penelitian selanjutnya diharapkan adanya sistem nilai otomatis yang real time, adanya timer, dan dengan menambahkan animasi atau augmented reality.

\section{Ucapan Terima Kasih}

Penulis berterima kasih kepada Kemenristek Dikti yang sudah memberikan dana hibah untuk penelitian ini.

\section{References}

Astiti, N. M. (2015). Analisa dan perancangan aplikasi pembelajaran matematika berbasis android. Konferensi Nasional Sistem Dan Informatika, 982-991.

Bransford, J., \& Stein, B. (1993). The Ideal Problem Solver. Centers for Teaching and Technology - Book Library. https://doi.org/10.1109/ISSNIP.2007.449 
6930

Djohan. (2007). Diktat Kalkulus I. Bandung: FMIPA ITB.

Fathurohman, E. A. P. and A. (n.d.). Pengembangan Perangkat Pembelajaran Dengan Model Ideal Problem Solving Berbasis Maple Matakuliah Kalkulus Ii, (2008), 12.

Lazuardy, G., \& Tonni, T. (2016). Perancangan Aplikasi Pembelajaran Kalkulus 1 Dengan Menggunkan Metode Computer Assited Instruction (Cai). JURIKOM (Jurnal Riset Komputer), 3(1), $12-17$.

Purnomo, E. A., Fathurohman, A., \& Budiharto. (2014). Keefektifan Model Pembelajaran Ideal Problem. Jkpm, 1(2), 7-11. 